\title{
PV Operated Fuzzy based DC Motor Controlled Centrifugal Pump used for Irrigation
}

\author{
Abhishek Dubey \\ M.Tech. Scholar \\ IET DAVV,Indore
}

\author{
Pratibha Singh, PhD \\ Asst. Professor \\ IET DAVV, Indore
}

\begin{abstract}
Due to the rapid depletion of conventional energy sources, there arises a need to use renewable energy sources for power generation in many applications. Sun is the most prominent renewable energy resource. Photovoltaic technology uses sun as its energy source, which is being mostly used now a day.

This paper presents a model which is designed for generating electricity used for irrigation. The model consists of Photovoltaic Panels, Fuzzy logic controller to control the speed of DC motor to a desired value, DC motor which is directly coupled with centrifugal pump. DC Motor is used in this model because of its favourable torque and robust speed control characteristics. The model is implemented using MATLAB/Simulink, which verifies the efficient torque and robust speed of the model.
\end{abstract}

\section{Keywords}

Photovoltaic Panels (PV), DC Motor, Centrifugal Pump, Fuzzy logic controller.

\section{INTRODUCTION}

Sun, as a source of solar energy, is the most inexpensive, universal source of energy available in the form of sunshine. Photovoltaic technology can convert the solar energy (photon) into electrical energy. Pumping application is the most prominent among the various available applications of PV.Instead of using batteries for storage, pumping system can be used as it is less expensive and have better lifetime. There are some important fields of application where the DC machines can have economic and technical advantage. Hence a pumping system based on DC motor can be implemented due to its favorable torque and robust speed characteristics that can be varied over a wide range while retaining high efficiency. Fuzzy logic based approach is applied for the effective operation of DC motor.

The paper presents a simulation and theoretical implementation of a method of speed control of a dc motor using fuzzy logic controller. The available fuzzy logic development kit can be applied to the theoretical development of fuzzy controller which shows that the simulation results are similar to the theoretical results to achieve the optimum control of speed [2].

The comparative analysis of BLDC motor based PV pumping system with two different controllers PI and the fuzzy controller is proposed. The PV source with incremental conductance (INC) algorithm is used to achieve maximum power. The system uses boost converter with MPPT, followed by three phase inverter coupled with BLDC drive system. SVPWM (Space Vector Pulse Width Modulation) technique is used to achieve constant speed which obtains constant throughput from the pump; the analysis shows that the fuzzy controller provides better response than the PI control [3]. The paper presents the speed control of dc motor using PID controller. The fuzzy logic controller is used to adjust the gains of PID on the basis of fuzzy rules for self-tuning of each parameter of PID controller. The study shows that the fuzzy self-tuning approach implemented on a conventional PID can improve the static and dynamic response of the system. The results show that the self-tuned PID controller gives better performance compared to conventional PID controller [4]. The battery less PV pumping system composed of DC-DC boost converter, DC-AC inverter, an induction motor and a centrifugal pump without battery and rotor speed sensor is designed in order to minimize the cost and maximizes the efficiency and reliability of the system, for this a fuzzy logic controller is used. The validity of FLC is tested and confirmed through simulation in different conditions [7].

A standalone photovoltaic system without battery storage which is controlled by FLC to achieve maximum power for generator and speed control is achieved by using the sliding mode technique. The different cases of availability of solar irradiance is studied which shows that the simulation results is satisfactory in both transient and steady state [9]. A method for speed control of DC motor using FLC is implemented using Lab VIEW program. The control voltage sent to the dc motor is applied on the basis of fuzzy rule base of speed error and change of speed error. The paper presents the comparison of results obtained using different controllers like FLC, PI and PID. The simulation results are satisfactory when DC motor with FLC controller overcome the disadvantages of conventional controller with respect to the variation of speed of dc motor [10].

\section{MODEL DESCRIPTION}

\subsection{Photovoltaic Pumping System}

Figure 1 shows the block diagram of proposed model.

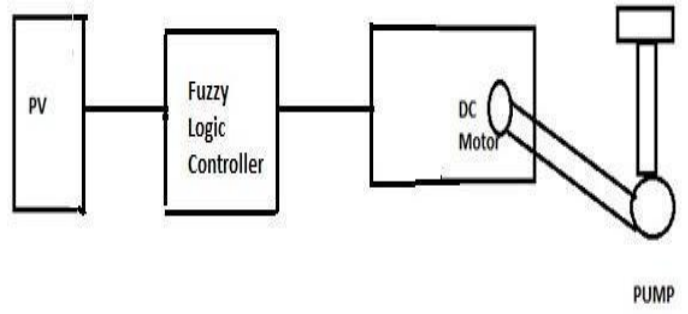

Fig 1: Structure of the photovoltaic pumping system 


\subsection{Motor Simulink Model}

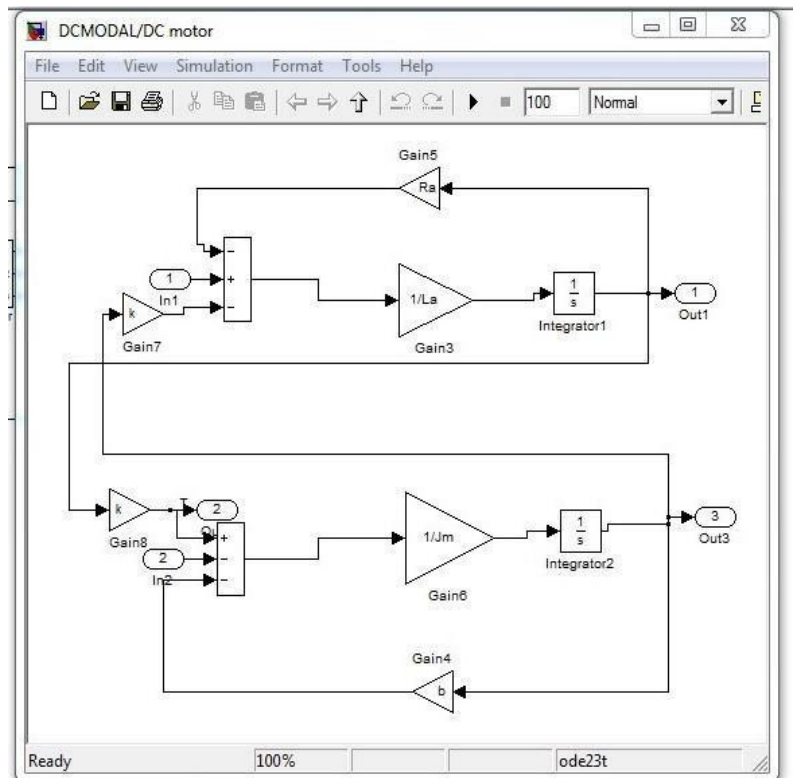

Fig 2: Simulink Model of DC Motor

\subsection{Fuzzy Logic Controller}

Fuzzy logic uses a knowledge based or a rule based controller, which consists of input, processing and output stages. Fuzzy Logic system is a system that processes analog values as logical variables which can take on continuous values ranging between 0 and 1 , rather than the digital logic, that takes on discrete values like true or false.

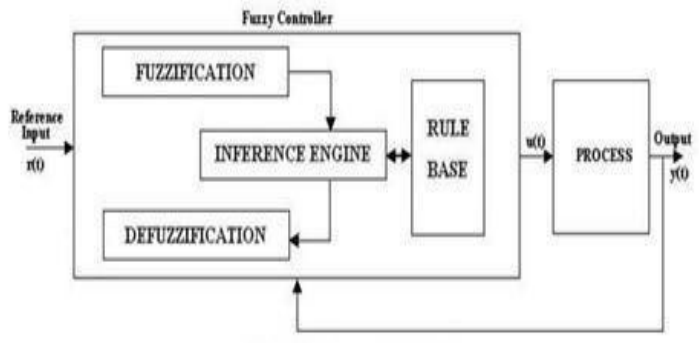

Fig 3: Fuzzy Logic Controller

Components of a Fuzzy Controller:

- Preprocessing

- Fuzzification

- $\quad$ Rule Base

- Defuzzification

- $\quad$ Post processing

The inputs to the Self-tuning Fuzzy Controller are speed error "e (t)" and Change-in-speed error "de (t)".

$\mathrm{e}(\mathrm{t})=\mathrm{wr}(\mathrm{t})-\mathrm{wa}(\mathrm{t})$

de $(\mathrm{t})=\mathrm{e}(\mathrm{t})-\mathrm{e}(\mathrm{t}-1)$

Using fuzzy control rules the output control is adjusted, which constitute the self control of D.C. machine.

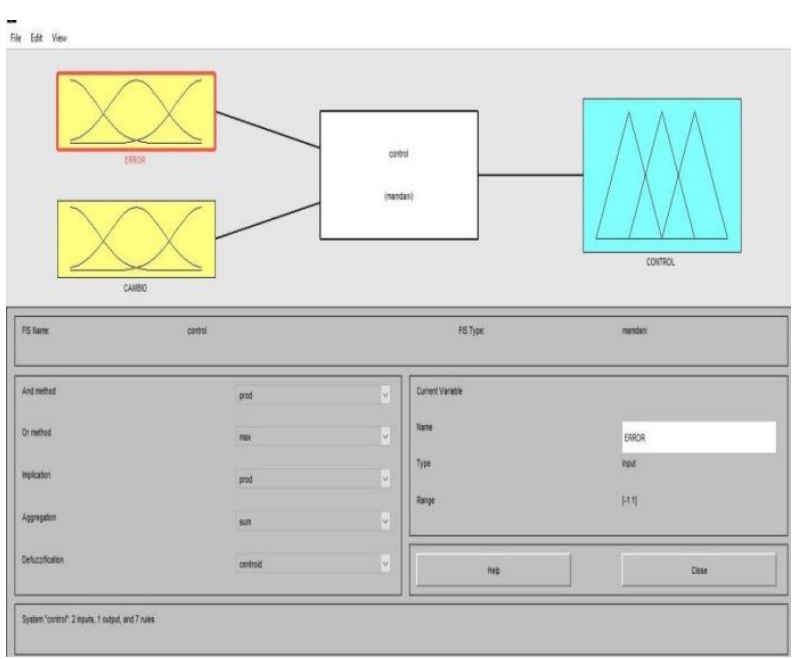

Fig 4: FIS Editor

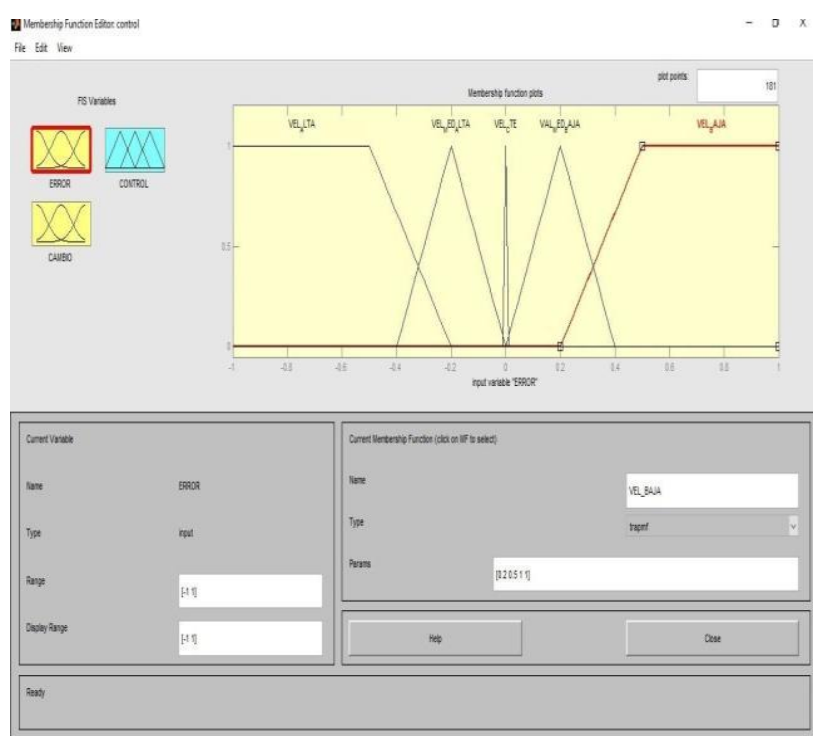

Fig 5: Membership Function

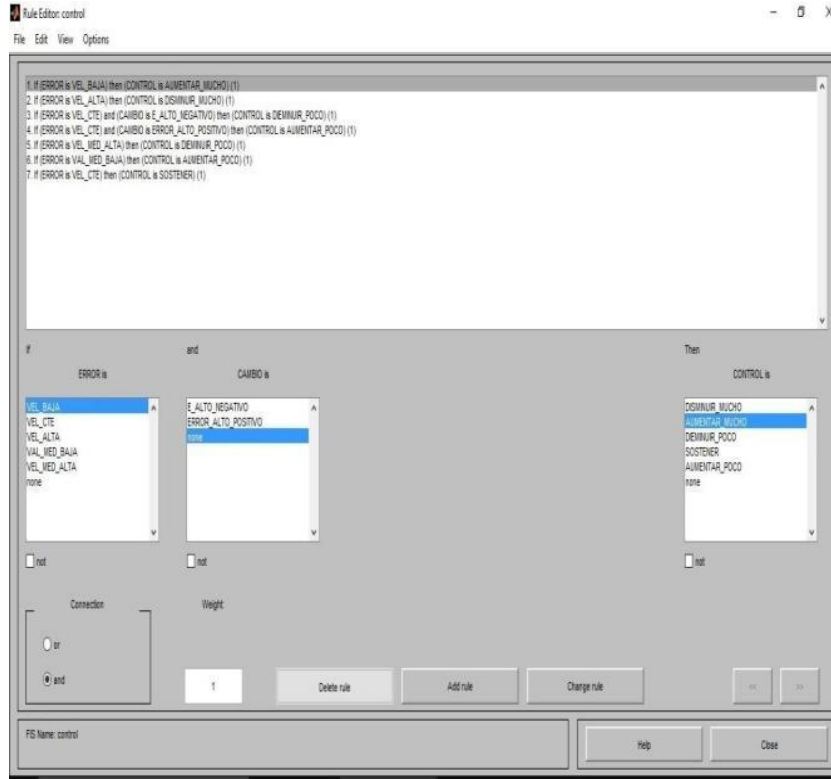

Fig 6: Rule Editor 


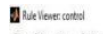

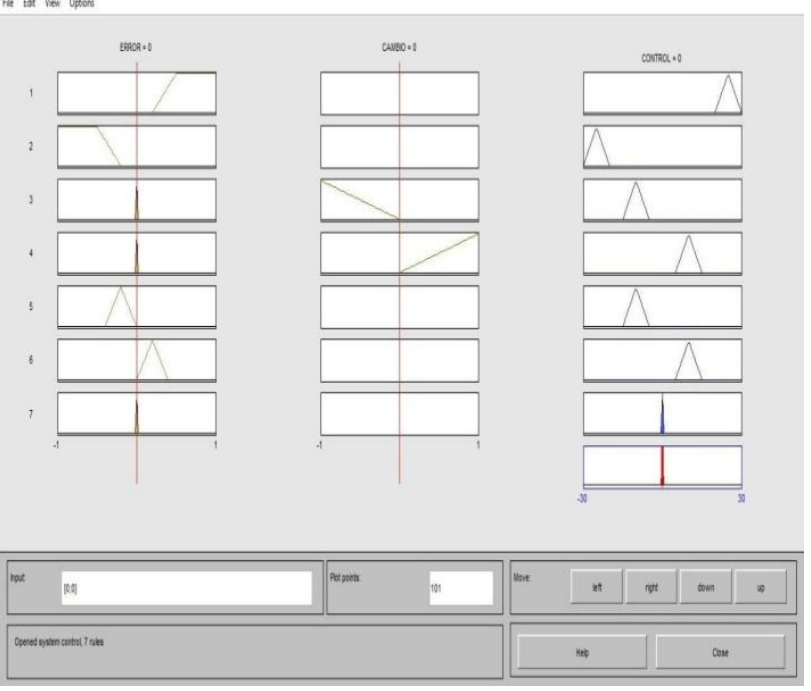

Fig 7: Rule Viewer

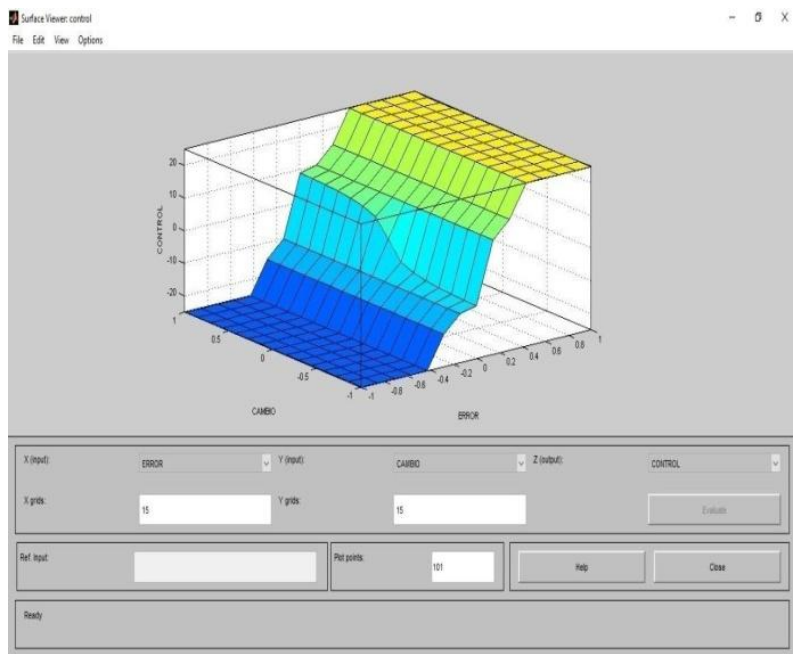

Fig 8: Surface Viewer

\subsection{Centrifugal Pump Simulink Model}

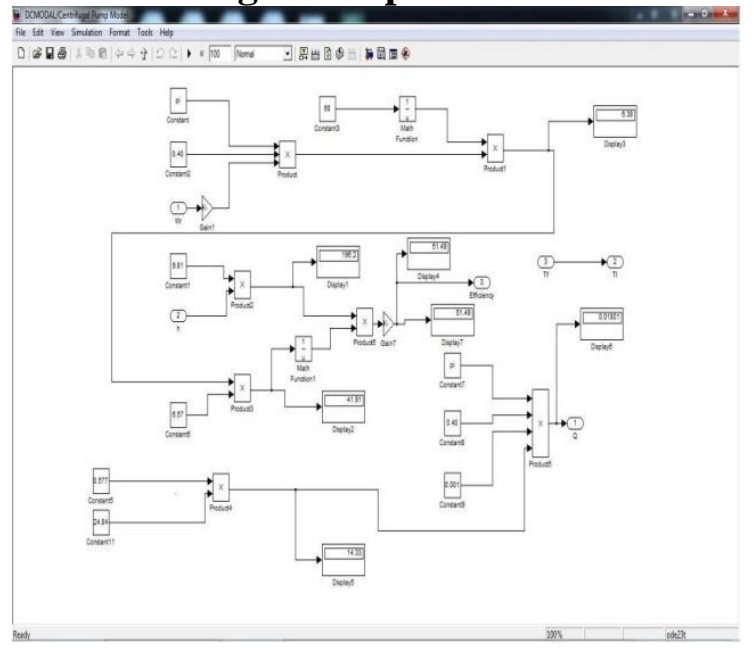

Fig 9: Simulink Model Of Centrifugal Pump
3. SIMULATION AND RESULTS 3.1 Simulink Model of Proposed System

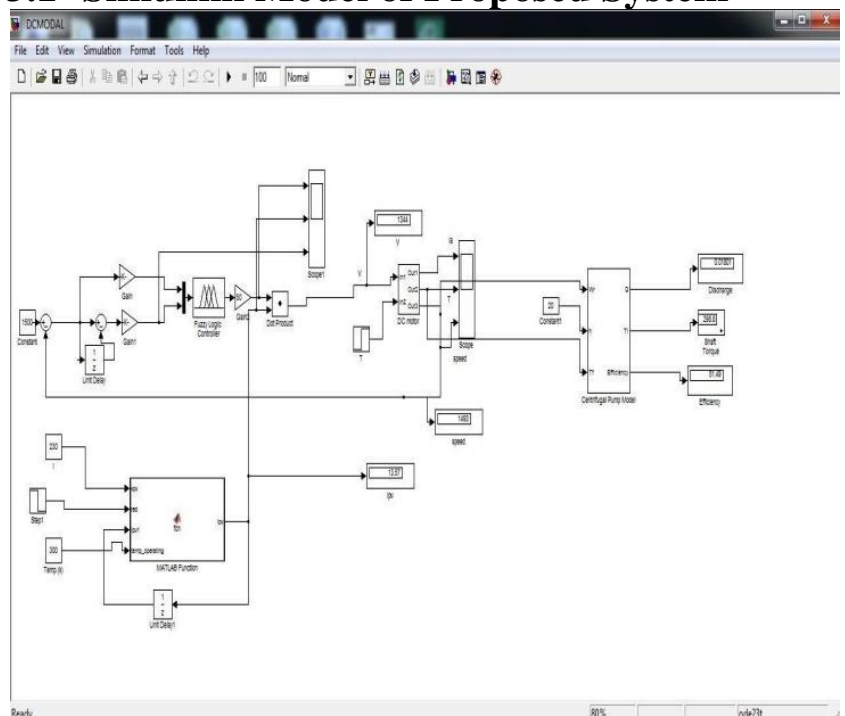

Fig 10: Simulink Model Of fuzzy based DC motor Pump

Case 1: When constant is 800RPM

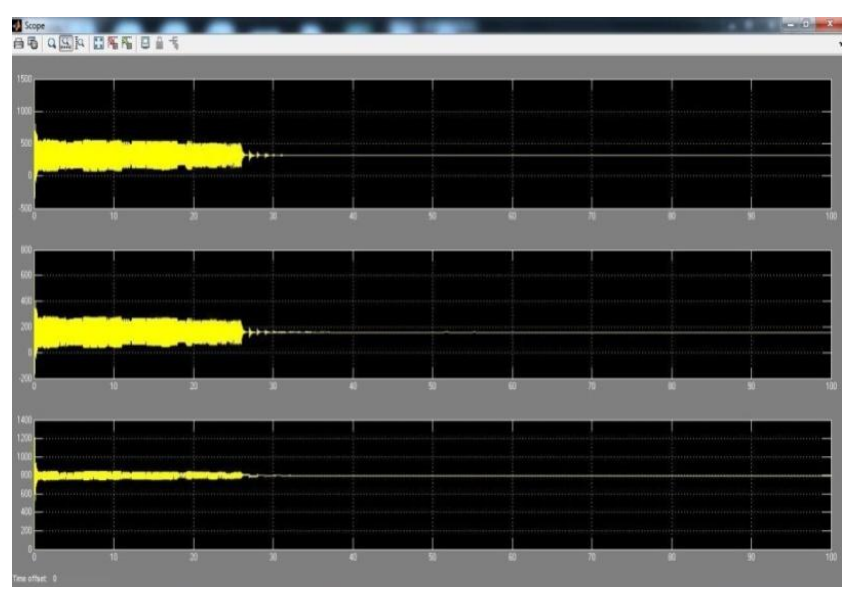

Fig 11: Armature Current, Torque and Speed

Case 2: When constant is 1000RPM

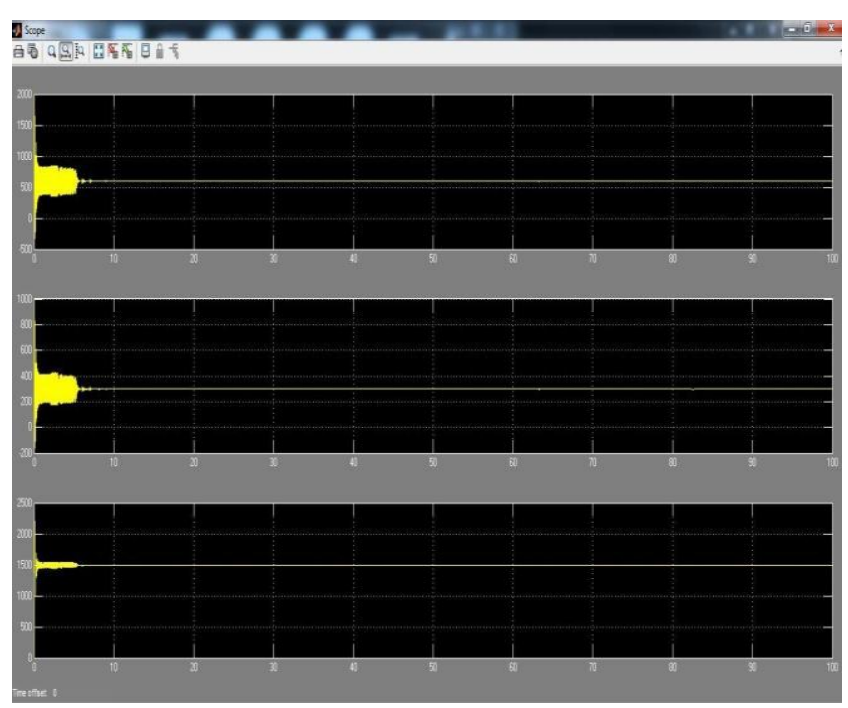

Fig 12: Armature Current, Torque and Speed 
Case 3: When constant is 1500RPM

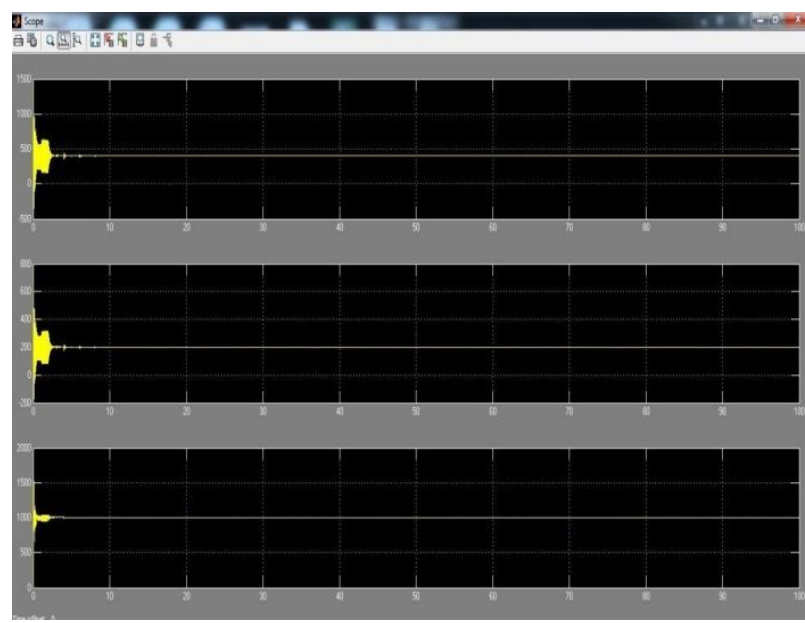

Fig 13: Armature Current, Torque and Speed

Table 1. Comparitive Analysis at Different Reference Speed

\begin{tabular}{|l|c|c|}
\hline $\begin{array}{c}\text { Constant } \\
\text { (Reference Speed) }\end{array}$ & Efficiency & Settling Time \\
\hline Case 1: 800 RPM & $36.6 \%$ & 26 Secs \\
\hline Case 2: 1000 RPM & $47.27 \%$ & 6 Secs \\
\hline Case 3: 1500 RPM & $51.49 \%$ & 6 Secs \\
\hline
\end{tabular}

\section{CONCLUSION}

A battery less low cost model of PV operated pump is designed for irrigation purpose. This paper has evaluated an effective control structure using the Fuzzy logic concept for DC Motor. The Fuzzy logic strategy enlightens a way to control the flow of the pumping station. The system optimizes power generated by the photo voltaic generator according to the irradiance and the temperature, which allows the station to operate at optimal operating point. Simulation results are satisfactory in terms of speed and torque characteristics.

The output of the DC motor is controlled at 1500 constant value, the efficiency is increased to $51.59 \%$.The output of PV module is fairly constant and also boosted by fuzzy controller which is enhancing the performance of the centrifugal pump. The motor will best perform from speed ranging from 1000 to 1500 RPM.

The present work deals with the modeling of centrifugal pump using PV Panel and its drive including Fuzzy controller for DC Motor. A design with low cost is suggested in this paper. Although the technology has been widely used in irrigation purpose, but it suffers from the issue of high maintenance of DC motor. This work can be extended in future by replacing the DC motor with Brushless DC motor (BLDC), which is easy to maintain. Also, other controllers like, sliding mode controller can be used to get the optimized results. An Induction motor, instead of DC Motor can also be used for the same model \& it provides better results in comparison with DC motor but the cost of the system will be very high, hence a low cost model using AC supply can also be suggested for the same.

\section{REFERENCES}

[1] P.Singhai, S.Gupta, R.Keswani, "Optimization of PV output for CentrifugalPumping System Operated by Induction Motor", International Journal of AdvancedScientific and Technical Research, Issue 5 volume 4, pp. 663-673, July-August 2015.

[2] Ravinder Kumar and Vineet Girdhar,"High Performance Fuzzy Adaptive Control for D.C. Motor",International Archive of Applied Sciences and TechnologyIAAST, Vol 3 [3], September 2012.

[3] Pandikumar Maniraj, Ramaprabha Ramabadran, Ranganath Muthu,"Analysis of Controllersfor Photovoltaic fed Brushless DC Motor basedWater Pumping System", Applied Mechanics and Materials, Vol. 787 (2015), pp 838-842,Feb 2015.

[4] Umesh Kumar Bansal and Rakesh Narvey "Speed Control of DC Motor Using Fuzzy PID Controller",Advance in Electronic and Electric Engineering, ISSN 2231-1297, Volume 3, Number 9 (2013), pp. 1209-1220.

[5] S. Abdourraziq, R. El Bachtiri, Abdourraziq Med Amine,"Modeling of aphotovoltaic pumping system using centrifugal pump and DC motor", Sustainabilityin Energy and Buildings: Research Advances, Vol. 2, pp. $1-6,2013$.

[6] A. Terki, A. Moussi, A. Betka, N. Terki,"An improved efficiency of fuzzy logic control of PMBLDC for PV pumping system, Elsevier, Vol. 36, pp. 934-944, 2012.

[7] M. Bahloul, L. Chrifi-Alaoui, M. Souissi, M. Chaabane, S. Drid," Effective Fuzzy Logic Control of a Stand-alone Photovoltaic Pumping System", Vol.5, No.3, April 2015.

[8] Mehdi Ouada , M.S Meridjet, M Saad Saoud, Talbi," Increase Efficiency of Photovoltaic Pumping System Based BLDC Motor Using Fuzzy Logic MPPT Control", Vol. 8, No. 3, pp. 104-113, July 2013.

[9] H. Bouzeria, C. Fetha, T. Bahi, L. Rachedi, "Sliding mode control of the speed pumping system Supplied by a Photovoltaic generator", Conférence Internationale des Energies Renouvelables (CIER'13) Sousse, Tunisie, Vol. 2, 2013.

[10] Salim, Jyoti Ohri, Naveen," Speed Control of DC Motor using Fuzzy Logic based on LabVIEW", Volume 3 , Issue 6, June 2013.

[11] K. B. Rohit, Prof. G. M. Karve, Prof. Khatri, "Solar Water Pumping System",International Journal of Emerging Technology and Advanced Engineering, Volume 3,Issue 7, pp. 2250-2459,July 2013. 